\title{
HÁ UMA POSSIBILIDADE DE RESPONSABILIDADE INTERNACIONAL DO CENÁRIO INTERNACIONAL EM SI? O CASO DO RUANDA
}

\author{
IS THERE ANY POSSIBILITY OF INTERNATIONAL LIABILITY OF THE INTERNATIONAL \\ SCENARIO AS ITSELF? THE RWANDAN STUDY CASE
}

Frédéric Walthère Joachim Pili ${ }^{*}$

\begin{abstract}
Resumo:
Estudo sobre a possibilidade de responsabilidade daquilo chamado comumente comunidade internacional. Estudo de caso a partir dos eventos no Ruanda e das reações da comunidade internacional e dos mecanismos subjacentes.

Palavras-chave: Comunidade internacional. Sociedade internacional. Responsabilidade internacional. Ruanda. Genocídio. Organização das Nações Unidas.
\end{abstract}

\begin{abstract}
:
Study about the possibility of liability of what is called usually international community. Study case about the Rwandan events and reactions of international community and its mechanisms.
\end{abstract}

Keywords: International community. International society. International liability. Rwanda. Genocide. United Nations Organization.

Introdução

Tradicionalmente, quando se pensa em responsabilidade internacional, pensamos no ilícito cometido pelo Estado, especialmente no que diz respeito ao direito humanitário.

Mas podemos estender essa noção ao cenário internacional em si? ${ }^{1}$ Afinal de contas, responsabilidade e personalidade são intimamente ligadas no Direito Internacional. (ACCIOLY; SILVA; CASELLA, 2016. p. 377).

No presente estudo, queremos ver se pode haver a responsabilidade internacional do próprio cenário internacional, depois de tentar uma definição de conceito

\footnotetext{
* Mestrando em Direito Internacional pela Faculdade de Direito da Universidade de São Paulo. Bacharel em História pela Universidade de Liège (Bélgica), detentor de um DEA (Diplôme d'études approfondies en relations internationales et droit européen) pela mesma Universidade.

1 Aqui usaremos no início deste trabalho a expressão "cenário internacional" para designar o que chamamos usualmente de comunidade internacional. Veremos a seguir que existe outra expressão, segundo nós tecnicamente mais correta: sociedade internacional. A expressão cenário internacional traz também inúmeras interrogações, mas acreditamos que seja a melhor forma de se expressar...
} 
um tanto difícil de se enxergar. Isso é desejável, claro, sobretudo na era da responsabilidade de proteger, mas é possível?

$\mathrm{Na}$ doutrina, responsabilidade e personalidade jurídica estão intimamente ligadas. Ora, desde o julgamento da Corte Internacional de Justiça de 1949, a personalidade jurídica da ONU e das demais organizações internacionais é admitida. Será que podemos estender ainda mais a responsabilidade internacional?

A ideia da comunidade/sociedade internacional

Mas afinal, como definir a comunidade internacional? E o termo comunidade seria o mais apropriado?

Uma reação natural é a de escolher apenas um fator. Veremos em seguida que não se apresenta como a melhor forma de se ver o problema.

Então: e o cenário internacional? Como se configura? É apenas uma expressão usual sem nenhuma realidade se confundindo com a ONU?

Uma primeira maneira de observar o cenário internacional é a de se levar em conta apenas os grandes fóruns internacionais, como, por exemplo, a Assembleia Geral da ONU. Isso não nos parece suficiente. De fato, é o que costuma acontecer no cotidiano e nos grandes veículos jornalísticos. Esta maneira de pensar apresenta uma grande vantagem: sua praticidade. Porém, há um grande problema: a ONU tem limites temporais - começou a existir em 1945 - e funcionais; papel de manutenção da paz mundial essencialmente. Certo, poderíamos apenas afirmar que a ONU é sua expressão formal; portanto, ONU e cenário internacional podem se confundir; um sendo a mera ferramenta de outro. Assim, permanece apenas o limite temporal. Mas não é tão simples. Voltando ao julgamento de 1949, a missão da ONU foi considerada como sendo de extrema importância para o cenário internacional (dos Estados, mas também dos indivíduos se levarmos em conta os recentes desdobramentos do Direito Internacional dos Direitos Humanos). O próprio julgamento faz referência ao papel da ONU como sendo fundamental para permitir a operacionalização e viabilizar a convivência internacional da comunidade dos Estados. (INTERNATIONAL COURT OF JUSTICE, 1949, p. 178, 185). Assim, existe uma diferenciação funcional. Na ótica do maior órgão judicial da ONU, não podem ser confundidas: a ONU é o instrumento jurídico de uma realidade social chamada comunidade internacional.

Um dos primeiros a perceber o cenário internacional como pano de fundo daquilo que se chamava ainda de direito das gentes (se não o primeiro) foi Christian Wolff. (CASELLA, 2015, p. 628-629). Ele escreveu sobre o assunto, em 1749, quase duzentos anos antes da Conferência de São Francisco. Assim, fica clara a antecedência histórica da noção de cenário internacional sobre a ONU. 
O que vale para a ONU, que é a organização internacional de maior amplitude e de maior relevância, vale para as demais que fazem parte da família ONU ou têm uma missão bem menos relevante.

Outra maneira de caracterizar o cenário internacional na visão comum é a política: o cenário internacional pode ser visto como uma hierarquização de Estados baseada na força ou no grau de cultura. Mas como defender que a força em si pode constituir um motivo duradouro de liderança de um país sobre os outros? Deveria haver outra razão de obedecer: uma é a de retomar o art. 38 do Estatuto da Corte Internacional de Justiça, que menciona as "nações civilizadas", ou seja, o grau de cultura e de desenvolvimento. Além do caráter obsoleto da expressão já criticada por vários autores (ACCIOLY; SILVA; CASELLA, 2016, p. 144), esta visão apresenta muitas perguntas. Civilizadas para quem? Sob qual critério? Em relação a que civilização e em qual de suas fases históricas? Com qual objetivo? Em nome de quais valores? E qual órgão (estatal ou não) dentro dessas nações teria a capacidade de representar a civilização no plano internacional e de manter sua liderança?

Poderíamos ainda pensar na opinião pública. Porém, os problemas logo começam a se multiplicar: existe uma opinião pública mundial? Qual seria seu canal? As agências oficiais ou privadas como Reuters, AFP, TASS? Os grandes órgãos da imprensa? Mas qual é a representatividade desses canais? As opiniões expressas refletem as opiniões do público? Como descrever de forma precisa uma realidade flutuante?

Por fim, há quem identifique cenário internacional e sociedade civil organizados. Além do fato de que as ONGs em termos mundiais funcionam por conta de um cadastro perante a $\mathrm{ONU}$, temos as mesmas dificuldades com a opinião pública.

Como podemos ver cada um desses fatores apresenta sua limitação conceitual se considerado isolado.

Outra forma de considerar o fenômeno é a de levar em conta esses vários fatores interagindo um com outro. Neste aspecto, haveria uma rede de impulsos e de retroações de um segmento sobre outro. Assim já o fazia Jesse Sidall Reeves em um dos primeiros cursos de Haia, consagrando sua palestra em mostrar a articulação de, pelo menos, três fatores: a sociedade dos Estados, instituições privadas (principalmente na época as igrejas) incluindo os órgãos da imprensa que chamaríamos hoje de organizações internacionais. O palestrante ressaltava o papel fundamental da liberdade da impensa sobre o Direito Internacional, um debate, aliás, que continua extremamente atual. ${ }^{2}$

Reeves (1925, p. 85-87). O autor intitulou um capítulo inteiro, entre as páginas 72 e 90, à justiça e à opinião pública (La justice internationale et l'opinion publique), apenas cinco anos após o estabelecimento da Corte Permanente de Justiça Internacional. 
Após a definição dos elementos constitutivos da comunidade/sociedade internacional, como esta última funciona? Quais são suas características? É o que passamos a examinar.

Um conceito difícil de se enxergar

Comunidade ou sociedade? Velho debate iniciado por Ferdinand Tönnies, em 1887, no seu clássico Gemeinschaft und Gesellschaft. ${ }^{3}$ Não cabe aqui retomar em detalhe suas implicações na Sociologia. Vamos apenas destrinchar os elementos essenciais dos dois modelos de sociedade e aplicá-los ao cenário internacional.

Celso Albuquerque Mello no seu Curso de direito internacional nos ensina o seguinte:

existe uma corrente que nega a existência de uma comunidade/sociedade internacional, sendo o estado a mais elevada forma de vida social (!); outra corrente sustenta que se trata de comunidade internacional; por fim, há quem sustenta que é uma sociedade internacional. (MELLO, 2000, p. 47). (É o caso do autor dessas linhas).

Comunidade é um grupo animado por um ímpeto de agregação antes de qualquer escolha consciente. A participação dos membros é maior, devido a uma energia criada pelo prazer, pela memória, pelo habitus. ${ }^{4}$ A comunidade tem um caráter mais intenso. Ela liga os membros por uma dimensão essencial do seu ser, participando no mais profundo da sua vida. (TRUYOL Y SERRA, 1960, p. 573). A sociedade implica uma relação puramente utilitarista, sem nenhuma implicação íntima; ela pressupõe a vontade consciente e declarada de participar, mas em um grau menor. Mello (2000, p. 47); Truyol y Serra, (1960, p. 573).

O autor dessas linhas rejeita por óbvio a tese da inexistência da comunidade/ sociedade... Mas também é inegável que exista uma realidade acima ou ao lado dos Estados. Nenhum Estado pode se permitir ignorar o mundo ao redor. Até para manter a própria independência...

Mas é uma sociedade ou uma comunidade? O autor diria ambas! Explicando melhor: é inegável que há elementos inerentes que levam quase naturalmente ao surgimento de um Estado e à sua participação aos assuntos do mundo. Isso configura a comunidade. Por outro lado, é necessário o acordo de vontade para o reconhecimento do Estado. Isso

3 Tönnies (1922). A terceira parte inteira era consagrada ao direito natural em relação à comunidade.

4 Mello (2000, p. 47). Bastante interessantes são os exemplos usados por Ferdinnand Tönnies: a relação entre a mãe e seu filho ou entre os noivos que vem respectivamente do instinto de sobrevivência ou do instinto sexual; ele acrescenta outras modalidades como a vizinhança. Tönnies (1922, p. 8-9). 
leva a uma sociedade. Não há nada original nessa visão. Tal era a posição de Antonio Truyol y Serra que colocava a atual configuração dos Estados como uma sociedade ao contrário da cristandade medieval vista como uma comunidade, por implicar a adesão a um credo religioso, elemento íntimo exigido dos indivíduos. (TRUYOL Y SERRA, 1960, p. 573-574). O autor acrescenta que prevalecem as características da sociedade, mesmo se alguns elementos da comunidade existem. Podemos citar o fato de que os Estados não nascem pela vontade dos seus membros e de que os Estados mantêm uma espécie de vizinhança marcada por um instinto de autopreservação.

Vale lembrar que a Corte internacional de justiça no julgamento já citado, de 1949, tende a usar a expressão de comunidade. ${ }^{5}$ Mas o diretor da biblioteca da paz (quase) contemporâneo ao julgamento de 1949, Bartholomeus Landheer, usa a expressão sociedade internacional no seu curso em Haia, em 1957. (LANDHEER, 1957, p. 27).

A título de exemplo: a crise ruandesa

Se existem vários fatores interagindo entre si, como aquilo funciona? Vamos usar o caso do Ruanda, em 1994, para entender melhor as articulações entre esses elementos. Por isso, usaremos a imprensa da época por meio de artigos de Ciência Política e Sociologia que tiveram como foco principal a imprensa americana, britânica, francesa e belga.

A primeira etapa foi a notícia de que houve um atentado no dia 6 de abril de 1994 contra o avião presidencial, provocando a morte do presidente Habyarimana. É bem verdade que a opinião internacional vinha sendo sensibilizada pela guerra civil naquele país, desde outubro de 1990, e a entrada de refugiados tutsis desde Uganda, organizados dentro de um movimento armado chamado Front patriotique rwandais (FPR). ${ }^{6}$ Mas ninguém na mídia internacional previa o desastre.

Porém, a catástrofe era previsível: entre 1990 e 1993, aproximadamente 2 mil pessoas já haviam sido exterminadas, de acordo com um plano sistemático, verdadeira preparação para o genocídio no âmbito nacional de 1994. Esses massacres eram organizados, provocados por uma propaganda maciça de ódio, aumentados pelo fechamento das vias de escape dos possíveis sobreviventes e pela participação das autoridades locais. (MELVERN, 2006, p. 94).

\footnotetext{
5 Em apenas duas menções a uma comunidade dos estados, o que relativiza o peso da importância de uma expressão sobre outra: International Court of Justice (1949, p. 178, 185).

6 Melvern (2006, p. 94); Pontzeele, (2008, p. 172).
} 
Na mesma noite do atentado, a guarda presidencial começa a massacrar em Kigali os líderes da oposição. No dia seguinte, apoiada por milícias do partido presidencial, o exército inicia a eliminação sistemática dos Tutsis. (PONTZEELE, 2008, p. 173).

Ninguém entendeu o racismo subjacente, na arena internacional. Mas para quem estava no terreno, de Ruanda, a situação era diferente: a Cruz Vermelha montava tendas enormes ao redor do hospital central de Kigali, em previsão daquilo que todo mundo sentia o que ia acontecer. Havia a presença de milicias armadas nas ruas da capital e boatos de listas de pessoas a serem eliminadas. Um jornal local havia até publicado um artigo em que foi revelada a próxima solução final do problema tutsi. ${ }^{7}$

As tropas da ONU começaram a chegar em dezembro de 1993 para a manutenção da paz, em um momento em que já era tarde demais. A tropa era pequena demais, ainda mais levando em conta um ambiente extremamente hostil. Ela tinha um mandato frágil e uma capacidade mínima. (MELVERN, 2006, p. 95, 97).

Logo após o atentado, que provocou no dia 6 de abril a morte de Habyarimana e de Cyprien Ntaryamira, respectivamente presidente do Ruanda e do Burundi, começa o massacre das lideranças tutsi e hutu moderada. Aqui vai ocorrer a morte de dez capacetes azuis belgas que protegiam a primeira-ministra do país. A morte destes capacetes azuis vai provocar a retirada do contingente belga presente nas tropas da ONU dentro de 24 horas, confortando assim nos fóruns mundiais, especialmente na Assembleia Geral e no Conselho de Segurança da ONU, uma reação paradoxal: o horror e a angústia diante daquilo que está se preparando e a covardia - não há outra palavra - em mandar mais tropas no terreno para evitar a catástrofe. Nas quatro primeiras semanas do desastre, em que 10 mil pessoas morrem por dia, o Conselho de Segurança nem sequer discute o assunto! ${ }^{8}$

Podemos desde já destacar uma explicação por esta inércia: os Africanos apenas são capazes de massacres tribais, mais ou menos espontâneos, não de um genocídio, que pressupõe um planejamento. Os massacres são puras manifestações de violência espontânea. Esta visão permite retirar o peso da culpabilidade dos Ocidentais, pois a violência é a última manifestação de uma lenta evolução interna, puramente africana, deste povo. ${ }^{9}$

Nos casos francês e belga, que tinham uma experiência do terreno e um conhecimento mais íntimo do país, isso pode ser explicado assim: o fim dos esquemas idelógicos baseados na divisão entre Oeste e Leste e a falta de especialistas do continente africano. Porém, vale ressaltar, que esta visão, dominante na imprensa de língua inglesa,

\footnotetext{
$7 \quad$ Melvern (2006, p. 95). Um Francês presente em Gisenyi em junho de 1994 apresenta como fato a existência de listas de pessoas a eliminar. (GODDING, 1994, p. 175).

$8 \quad$ Melvern (2006, p. 98); Dowden (2004, p. 286); Willame (1994, p. 122).

9 Melvern (2006, p. 93-104); Dowden (2004, p. 288-289); Wall (1997, p. 126).
} 
entrava em colisão com outra que a colocava em xeque explicitamente. Em particular, Colette Braeckman e Marie-France Cros, duas jornalistas belgas, rejeitavam energicamente esta leitura tribal por conta da inação da sociedade internacional e mostravam, junto a outros colegas, que existia um plano por trás dos eventos. (PONTZEELE, 2005, p. 323$325)$.

O noticiário internacional tampouco contribuiu: no dia 27 de abril ia ocorrer a primeira eleição aberta a todos os cidadãos da África do Sul. Muitos jornalistas esperavam por um derramamento de sangue ali, devido aos tumultos causados pelos movimentos zulus que não haviam assinado um acordo para participar dos acordos de paz. Mas isso tudo se resolveu poucos dias antes das eleições. (DOWDEN, 2004, p. 287).

Voltando às mídias, como depois demostrou a primeira investigação internacional (ERIKSSON, 1996), o fracasso dos órgãos de imprensa ocidental em descrever adequadamente os eventos no Ruanda provocou a indiferença internacional e a inação que possibilitou o genocídio. Este fracasso não provocou uma pressão da opinião pública sobre os membros-chave da ONU para que haja um reconhecimento do genocídio como tal e a resposta da sociedade internacional. ${ }^{10} \mathrm{~A}$ mídia internacional demorou três semanas para dar uma cobertura completa e lúcida sobre o que ocorria. Neste ínterim 250 mil pessoas já tinham sido assassinadas. (KUPERMAN, 2003).

O periódico The Times no dia 11 de abril ainda chamava por um cessar-fogo entre as partes daquilo ainda considerado como uma guerra civil. Naquele mesmo dia, o jornal belga De Standaard mencionava atos de terror, mas nos dois lados. Por volta da mesma época, as agências de imprensa indicavam que o governo propôs um acordo de paz rejeitado pelos rebeldes tutsis. Os noticiários Le Monde e The Times explicavam os receios dos Hutus que temiam represálias dos Tutsis. (KUPERMAN, 2003).

No dia 21 de abril, retroação da opinião pública sobre a ONU, a Resolução n. 912 do Conselho de Segurança, apesar de reconhecer a morte de milhares de civis, incluindo mulheres e crianças, apesar dos ataques contra as forças da ONU, chama a comunidade internacional (a expressão usada na resolução) a mais envolvimento nos assuntos do Ruanda. O Conselho reduz a missão da MINUAR a uma missão de bons ofícios, tentando exercer a assistência humanitaria onde seria possível. ${ }^{11}$ Porém, Roméo Dallaire, tenente-coronel canadense responsável pela força de paz no Ruanda, já havia falado em genocídio em relatório à ONU. Dallaire estimava que uma força internacional de 5,5 mil soldados poderia ter posto fim ao genocídio. Ninguém levou em consideração.

10 Melvern (2006, p. 95-96). Cruelmente, Richard Dowden comenta que o jornal britânico The Tiimes em abril de 1994 se preocupava com o futuro... dos gorilas. Dowden (2004, p. 286); Kuperman (2003).

11 United Nations (1994, p. 2-3); Willame (1994, p. 129). Vale ressaltar aqui o erro de Colette Braeckman, grande jornalista belga, que escreveu que foi essa resolução que diminuiu o contingente das forças de paz para 500 soldados: Braeckman (2004, p. 20). 
Em maio, diante da falta de soldados, aproximadamente 470 soldados, Dallaire podia apenas garantir a segurança dentro de quatro campos de refugiados (havia 91 no total). (MELVERN, 2006, p. 96-98).

Porém, novamente o periódico The Times, em 12 de abril, já anunciava que o objetivo prioritário dos assassinos eram os Tutsis e os Hutus que apoiavam os acordos de paz. Dois dias mais tarde, a mesma jornalista, Catherine Bond, no mesmo jornal, denunciava a ação planejada de milícias treinadas. Pouco a pouco, ao longo do mês, a imprensa britânica passa de massacres tribais a verdadeiro genocídio. (DOWDEN, 2004, p. 289).

Mas paralelamente, os jornais anunciavam a diminuição das matanças, um contrassenso. Pior, as estimativas dos jornais eram inferiores à realidade em um fator 10 . Assim, The New York Times anunciava a morte de 8 mil a 10 mil pessoas somente em Kigali. Seis dias depois, em 16 de abril, The Guardian fazia referência a 20 mil mortos no país inteiro, número retomado no dia 18 pelo New York Times. Em 18 de abril, de forma inexplicável, os jornais ocidentais anunciavam o fim dos massacres, enquanto o genocídio atingia seu ápice... Mais lúcido, o rádio belga La Une explicava que o massacre continuava, mas havia a ausência dos jornalistas ocidentais, que tinham deixado o país. (KUPERMAN, 2003).

A primeira menção a um genocídio foi feita no jornal The Guardian em 28 de abril de 1994. Mas era um pequeno artigo de poucas linhas no meio do jornal. Um fato secundário em suma... No dia 4 de maio, o mesmo jornal constatava com pessimismo que havia pouco a ser feito no plano internacional para pôr fim àquilo que estava em curso. (MELVERN, 2006, p. 96-97).

Vale ressaltar que os jornais apenas descreveram, até o dia 22 de abril, o que aconteceu na capital, sem levar em consideração o resto do país. Somente em 22 de abril que o The New York Times mencionou o caos provocado no resto do país. (KUPERMAN, 2003).

Voltando à arena internacional, as sessões do Conselho de Segurança são secretas, contrariando, aliás, os desejos dos fundadores da ONU que privilegiavam reuniões públicas, justamente para pressionar a atuação das grandes potências. Ora, esta cultura do segredo justamente contribui por diluir a responsabilidade em caso de inação. Sabemos hoje que ONGs internacionais como Oxfam já haviam informado o governo britânico do genocídio no meio de abril. Mas não conseguiram tirar o foco sobre a guerra civil. Nem o governo americano nem o governo britânico usou o termo genocídio para evitar a aplicação do art. VIII da convenção sobre a prevenção e repressão do genocídio, de 1948. (MELVERN, 2006, p. 96-97; 99; 102).

Foi apenas no meio do mês de maio que a ONU votou a considerar um mandado alargado à MINUAR. Boutros-Ghali encarava, inclusive, operação militar de 
dissuasão e de demonstração de força no seu relatório de 13 de maio. Mas tivemos que esperar até o dia 8 de junho para que fossem criadas zonas de segurança. (WILLAME, 1994, p. 129).

A explicação é de que a ONU tinha a ex-Iugoslávia na sua agenda. Ruanda era considerado um país marginal e dentro da esfera de influência francesa. (MELVERN, 2006, p. 98). Possivelmente, a Administração Clinton queria evitar um novo drama como aquele que se sucedeu na Somália. (DOWDEN, 2004, p. 288).

Conclusão

Como vimos logo na introdução, responsabilidade internacional e personalidade internacional estão intimamente ligadas. Como responsabilizar algo tão volátil e tão vago como a comunidade internacional? Como dar um estatuto jurídico àquilo que é apenas uma interação entre três elementos, as arenas internacionais, a opinião pública ainda em larga medida nacional, mas cada vez interessada pelos assuntos internacionais e a sociedade civil organizada?

Vimos que a opinião pública tem um papel de destaque nesta questão. Sim, em grande parte, ela é ainda presa em seu contexto nacional, mas cada vez mais ela se interessa pelos assuntos internacionais. Não foi infelizmente o caso no Ruanda em 1994... Provavelmente, foi aí que o cenário internacional deixou de funcionar de forma satisfatória. A cegueira das opiniões públicas, apesar das notícias divulgadas pelas ONGs no Ruanda, é o fruto da negligência ou do desprezo dos grandes órgãos da imprensa. Isso é grave: não permitiu a mobilização da opinião pública sobre os Estados e sua atuação na ONU, entre outras consequências.

Porém, como responsabilizar os órgãos da imprensa? Punir os jornalistas, a redação, fechar os jornais? Ridículo obviamente.

Mas podemos levar um obstáculo enorme a este assunto: somente o Estado é responsável internacionalmente no direito vigente. É fato. Não há como no atual Direito Internacional geral sustentar a existência da responsabilidade internacional da comunidade internacional em si.

Porém, seria um pouco simples terminar este trabalho desta forma. Como vimos acima, existe o direito da comunidade internacional de ver o conjunto dos Estados ajudarem a ONU em desempenhar sua função de maneira satisfatória. Se existe este direito ao funcionamento correto da ONU, há uma obrigação correlata de fazer tudo aquilo que for preciso para assegurar este bom funcionamento.

Esta constatação de bom senso tem, a nosso ver, implicações consideráveis em caso de violação maciça dos direitos humanos. Em particular, podemos pensar que neste caso ruandês, um serviço de inteligência próprio à ONU fez falta. Será que é possível 
e desejável - em um mundo já suficientemente vigiado por agências governamentais - a criação de tal organismo?

Mas o que aconteceu com as ONGs no ECO SOC? Vimos acima que a Cruz Vermelha aparentemente já tinha antecipado uma tragédia humanitária de enorme proporção. Não avisou a ONU? Se não, por quê? Em caso de resposta afirmativa, o que aconteceu?

São Paulo, abril de 2018.

\section{Referências}

ACCIOLY, Hildebrando; SILVA, Geraldo E. do Nascimento e; CASELLA, Paulo Borba. Manual de direito internacional público. 22. ed. São Paulo: Saraiva, 2016. p. 377.

BRAECKMAN, Colette. Rwanda, retour sur un aveuglement international. Le Monde Diplomatique, Paris, mars 2004. p. 20.

CASELLA, Paulo Borba. Direito internacional no tempo clássico. São Paulo: Atlas, 2015.

DOWDEN, Richard. Comment: the Rwandan genocide: how the press missed the story. A memoir. African Affairs, Londres, v. 103, n. 411, p. 283-290, Apr. 2004.

ERIKSSON, John. The international response to conflict and genocide: lessons from the Rwanda experience. March 1996. Disponível em: <https://www.oecd.org/countries/rwanda/50189495.pdf>.

GODDING Jean-Pierre. Aux origines du drame rwandais. Études - Revue Catholique D'intérêt Général, Paris, v. 381, p. 171-176, Sept. 1994.

INTERNATIONAL COURT OF JUSTICE. Reports of judgments, advisory opinions and orders. Reparation for injuries suffered in the service of the United Nations. Leyde: Société D'Éditions, 1949. p. 174-189.

KUPERMAN, Alan J. How the media missed Rwandan genocide. July 2003. Disponível em: $<$ https://www.hawaii.edu/powerkills/COMM.7.8.03.HTM>. Acesso em: 24 abr. 2018.

LANDHEER, Bartholomeus. Contemporary sociological theories and international law. Collected Courses of the Hague Academy of International Law, Leiden, v. 91, p. 1-103, 1957.

MELLO, Celso Duvivier de Albuquerque. Curso de direito internacional público. 12. ed. rev. e aum. Rio de Janeiro: Renovar, 2000.

MELVERN, Linda. Rwanda and Darfur: the media and the Security Council. International relations, London, v. 20, n. 1, p. 93-104, 2006.

MILLWOOD, David. (Ed.). The international response to conflict and genocide: lessons from the Rwanda experience. Odense: Strandberg Grafisk, March 1996. 
PONTZEELE, Sophie. Génocide au Rwanda. Les tensions du discours journalistique. Questions de communications, Paris, n. 8, p. 319-338, 2005.

. Le schème de la "guerre ethnique" dans la médiatisation des crises africaines: Burundi 1972 et Rwanda 1994. Les Cahiers du journalisme, Paris, n. 18, p. 166-182, 2008.

REEVES, J. S. La communauté internationale. RCADI - Recueil des cours de l'académie de la Haye, Paris, v. 3, p. 1-94, 1925.

TEMPLE-RASTON, Dina. Journalism and genocide. Columbia Journalism Review, New York, p. 18-19, Sep./Oct., 2002.

TÖNNIES, Ferdinand. Gemeinschaft und Gesellschaft: Grundbegriffe der reinen soziologie. 4. ed. Berlin: Karl Curtius, 1922.

TRUYOL Y SERRA, António. Genèse et structure de la société internationale. Collected Courses of the Hague Academy of International Law, Leyde, v. 96, p. 553-627, 1959.

UNITED NATIONS. Security Council. Resolution 912 (1994). 21 April 1994. Disponível em: $<$ http://unscr.com/en/resolutions/doc/912>. Acesso em: 29 abr. 2018

WALL, Melissa A. The Rwanda crisis. An analysis of news magazine coverage. Gazette, Londres, v. 59, n. 2, p. 121-134, April 1997.

WILLAME, Jean-Claude. Diplomatie internationale et génocide au Rwanda. Politique africaine, Paris, n. 55, p. 116-131, Octobre 1994. 